\title{
Identification of peri-prostatic neurovascular fibers before and after radical prostatectomy by means of diffusion tensor imaging (DTI) with clinical correlations: initial experience
}

\author{
SALVATORE SIRACUSANO ${ }^{1}$,ANTONIO B. PORCARO ${ }^{1}$, ALESSANDRO TAFURI ${ }^{1}$, RENATO \\ TALAMINI $^{3}$, ADAM J. CYBULSKI ${ }^{2}$ \\ Department of Urology, AOUI Verona, University of Verona, Verona (VR), Italy; \\ 2 Department of Radiology, AOUI Verona, University of Verona, Verona (VR), Italy \\ ${ }^{3}$ Epidemiology Unit CRO Aviano, Italy
}

\begin{abstract}
Aim To evaluate if Diffusion Tensor Imaging (DTI) is able to detect morphological changes of peri-prostatic neurovascular fibers (PNF) before and after robot-assisted radical prostatectomy (RARP) and if these changes are related to urinary incontinence (UI) and erectile dysfunction (ED). Materials and methods: From October 2014 and August 201726 patients with biopsy-proven prostate cancer underwent prostatic multi-parametric magnetic resonance imaging (mp-MRI) including DTI sequencing before and six months after, RARP. Images were analyzed by placing six regions of interest (ROI) respectively at the base, mid-gland and apex, one for each side, to obtain tractography reconstruction of the PNF. Patients were asked to complete an International Consultation Incontinence Questionnaire - Short Form (ICIQ-SF) and International Index of Erectile Function (IIEF-5) questionnaires before RARP and 6 months postoperatively. Fractional anisotropy (FA), number $(\mathrm{N})$ and length $(\mathrm{L})$ of PNF before and after RARP were compared by means of Student's t-test; Spearman test was used to evaluate the correlation between DTI parameters and questionnaires scores. We observed a significant difference in N values before and after RARP $(\mathrm{p}<0.001)$ and a negative correlation between IIEF- 5 score and post-operative FA values at both the right $(\mathrm{rho}=-0.42 ; \mathrm{p}=0.0456)$ and left $(\mathrm{rho}=-$ $0.66 ; \mathrm{p}=0.0006$ ) base of the prostate. DTI with tractography of PNF is able to detect quantitative changes in N, L and FA values in PNF after RARP. In particular we observed an inverse correlation between FA of PNF and ED at 6 months after RARP. Further investigations are needed to confirm this trend..
\end{abstract}

Keywords: MRI; Diffusion Tensor Imaging; RARP; Urinary continence; Erectile dysfunction

\section{INTRODUCTION}

In clinical practice, robot-assisted radical prostatectomy (RARP) is an effective option for treating prostate cancer (PCA) along with all clinical risk classes ${ }^{1}$. However, drawbacks related to the procedure include urinary incontinence (UI) and erectile dysfunction (ED) ${ }^{1}$. Nerve-sparing techniques during RARP have shown to reduce the risk of both UI and ED, whose rates vary from $89 \%$ to $42 \%$ and $32 \%$ to $18 \%$ for unilateral and bilateral nerve sparing, respectively ${ }^{1,2-6}$. Because the number of preserved periprostatic neurovascular fibers (PNFs) associates with erectile function recovery ${ }^{7,8}$, imaging visualization of these fibers is becoming an emerging issue ${ }^{9}$.

Multiparametric magnetic resonance imaging (mMRI), which combines T2-weighted (T2W) with dynamic contrast-enhanced (DCE-MRI) and diffusion-weighted imaging (DWI), has an important role for diagnosing and staging PCA ${ }^{1,10}$. Furthermore, MRI provides an excellent depiction of pelvic anatomy and also predicts the extent of NVB involvement ${ }^{8,11-12}$. Although MRI is able to assess extracapsular invasion of PCA, the visualization of PNFs remains still difficult ${ }^{12,13}$. Diffusion tensor imaging (DTI) is a new MRI modality in the field of Neuroimaging, it is noninvasive and provides a sharp depiction of central and peripheral nervous fibers ${ }^{14-24}$. Recently, it has been shown that DTI, which is based on the sensitivity of "anisotropic diffusion" of the water protons measured in a micro-structural environment of biological tissues, is able to map PNFs ${ }^{9,26-8}$. Indeed, the anisotropic diffusion represents a condition in which the diffusion of water protons is not casual or "Brownian" but oriented along a determined axis; furthermore, this condition occurs in biological tissues with a strictly orientated texture, such as nervous central and peripheral fibers, including the PNFs ${ }^{15}$. DTI is able to quantify this phenomenon throughout the measurement of Fractional Anisotropy (FA) for each single voxel in at least 6 non-collinear and non-coplanar directions; by the integration of FA of all voxels it becomes possible to represent the direction of nerve fibers in all three dimensions of space, giving both quantitative and qualitative anatomic information. The aim of the study is to evaluate if DTI is able to detect the changes of the PNFs before and after nerve-sparing RARP, and if these changes are related to UI and ED.

\section{MATERIALS AND METHODS}

\section{Study population}

A prospective study was carried out in collaboration between the Institute of Radiology and the Urology Department of the University of Verona. The study had institutional review board approval. Each patient provided informed signet consent for all MRI examinations.

In a period ranging from October 2014 to August 2017, the study collected 31 PCA patients underwent RARP with "nerve-sparing" intent. Exclusion criteria were absolute contraindications for the conduct of the MRI, severe post-surgical complications, failure to adhere to 6-month follow-up, disease relapse or death. Patients were classified according to the D'Amico cancer class risk categories ${ }^{29}$. Clinical staging was computed according to the 2002 American Joint Committee on Cancer staging system for PCA. RARP, which was associated with the unilateral or bilateral nerve-sparing technique, was delivered by the Si da Vinci Robot System (Intuitive Surgical, Inc, Sunnyvale, CA, USA) and was performed through the transperitoneal approach with antegrade prostatic dissection ${ }^{30,31}$. A transurethral 18 Fr Foley catheter was placed in all cases and the balloon was inflated with 7 cubic centimeters (cc) of physiologic solution. Before March 2017, a postoperative drain was placed in the pelvis, which was removed on a postoperative day (POD) one if the output was less than $150 \mathrm{~mL} / 24 \mathrm{~h}$. If the postoperative outcome was unevent- 
Table 1. MRI protocol

\begin{tabular}{|c|c|c|c|c|c|c|}
\hline Pulse Sequence & Plane & $\begin{array}{c}\text { Repetition \& } \\
\text { Echo Time } \\
\text { (ms) }\end{array}$ & $\begin{array}{l}\text { Section Thickness } \\
\text { (mm) }\end{array}$ & $\begin{array}{l}\text { FOV } \\
(\mathrm{mm})\end{array}$ & Flip angle & Duration \\
\hline T2 TSE & Axial & $4100 / 100$ & 4 & $380 \times 340$ & $90^{\circ}$ & 1'30" \\
\hline T2 TSE (HR) & Sagittal & $2650 / 90$ & 3.5 & $200 \times 200$ & $90^{\circ}$ & $1 ' 40$ ' \\
\hline T2 TSE (HR) & Coronal & $2500 / 100$ & 3.5 & $160 \times 160$ & $90^{\circ}$ & $35^{\prime \prime}$ \\
\hline T2 TSE (HR) & Axial & $3730 / 90$ & 3.5 & $160 \times 160$ & $90^{\circ}$ & 4'10" \\
\hline DWI & Axial & $4000 / 90$ & 3.5 & $300 \times 300$ & $90^{\circ}$ & 7'47'” \\
\hline DTI & Axial & $1449 / 88$ & 3 & $220 \times 220$ & $90^{\circ}$ & 3'14"' \\
\hline T1 DIXON Dynamic phase & Axial & $4 / 2$ & 3.5 & $200 \times 220$ & $90^{\circ}$ & $3{ }^{\prime} 17^{\prime \prime}$ \\
\hline b-SSFP & Axial & $5000 / 80$ & 6 & $400 \times 350$ & $90^{\circ}$ & 51 , \\
\hline
\end{tabular}

ful, patients were discharged on POD 4 with the catheter removed on POD 12 without cystography. Extended PLND was performed according to a standard template, which included the obturator fossa, external, internal and common iliac lymph nodes. The operating time was calculated as the interval between incision of the first laparoscopic port and suture of the last laparoscopic port. The surgical procedures were performed by two experienced surgeons. Prophylaxis of deep venous thrombosis with low molecular weight heparin was performed in all cases elected to RARP with extended PLND and with comorbidity risk factors ${ }^{30}$. In all cases, early mobilization was activated starting from the day

Figure 1A. Prostate apex

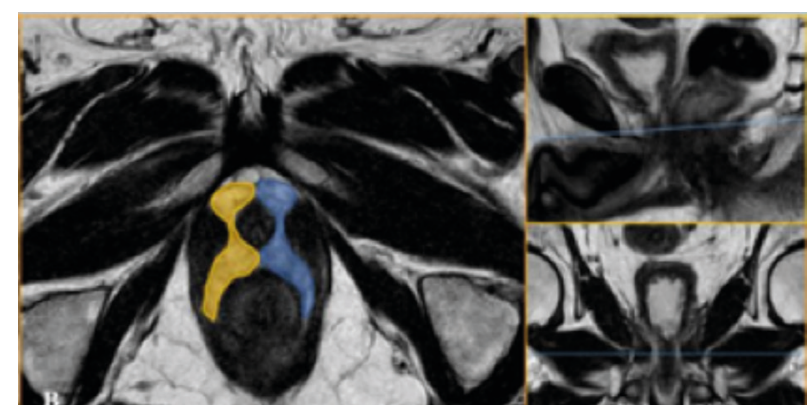

Figure 1C. The middle third of the prostate gland

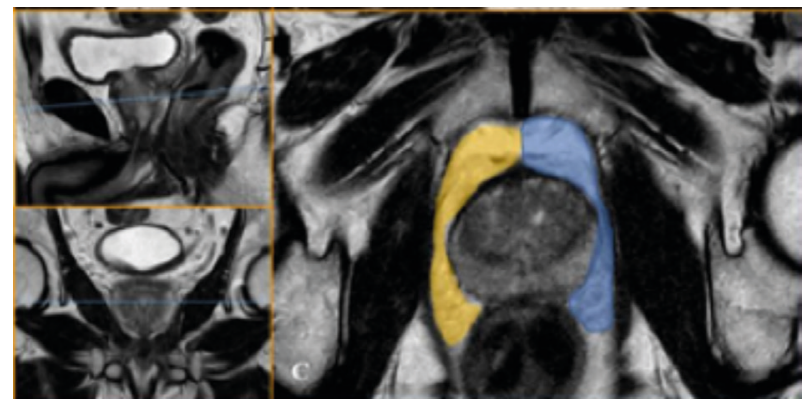

Figure 1E. Prostate base

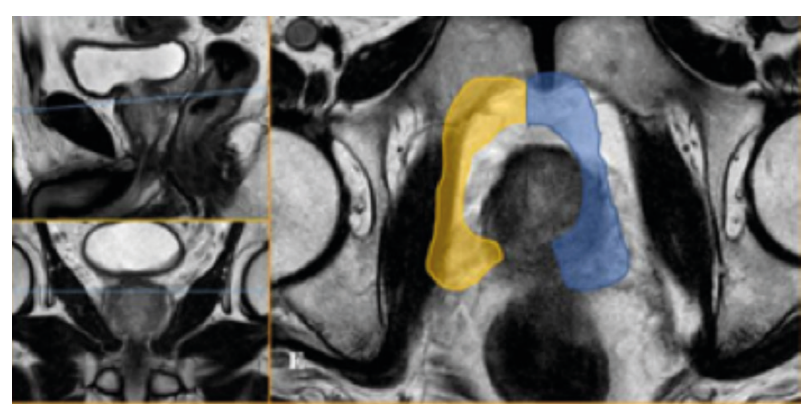

of surgery (POD 0). Deep venous thrombosis prophylaxis was prolonged till POD 28. In the surgical specimen, tumors were graded and staged according to the modified Gleason score system and TNM classification system ${ }^{1}$. All patients, before and six months after surgery, were assessed by the International Index of Erectile Function (IIEF-5 questionnaire $)^{32}$ and International Consultation Incontinence Questionnaire-Short Form, (ICIQ-SF) ${ }^{33}$.

MRI technique with DTI study

All MRI investigations were performed with DTI sequences on 1.5T (Ingenia, Philips Medical Systems, Eindhoven,

Fig. 1B. Equivalent plane to prostate apex in a post - RP MRI exam

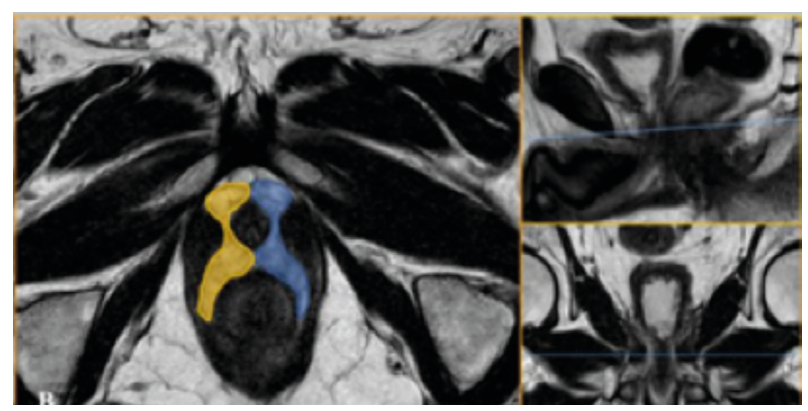

Fig. 1D. Equivalent plane to the third medium in post-RP MRI exam

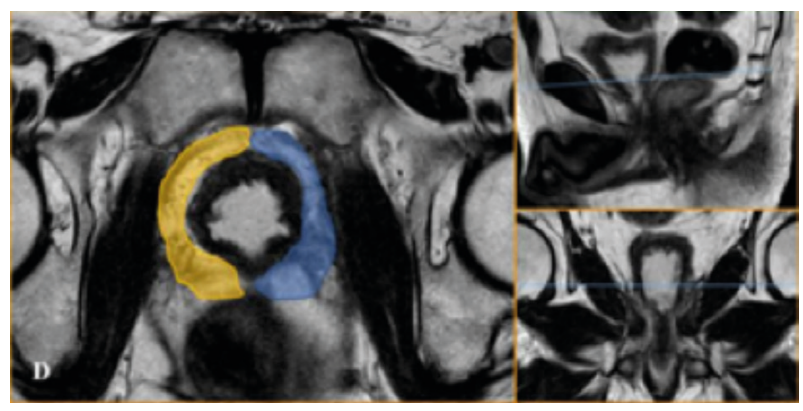

Figure 1F. Plane equivalent to the prostate base in post-RP MRI exam

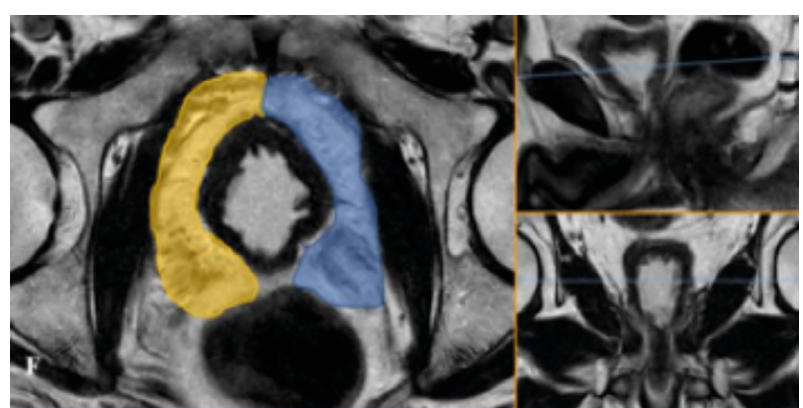


Table 2. Some clinical and pathological characteristics of 31 patients to undergo an radical prostatectomy nerve-sparing

\begin{tabular}{|c|c|}
\hline Characteristics & \\
\hline N. patients & 31 \\
\hline Age (years): Mean $( \pm \mathrm{SD})$ & $64.03( \pm 7.05)$ \\
\hline Total prostatic volume: Mean $( \pm S D)$ & $45.72( \pm 22.18)$ \\
\hline PSA*: Mean $( \pm$ SD $)$ & $9.05( \pm 11.42)$ \\
\hline Nerve-sparing right: N. (\%) & $24(77.4)$ \\
\hline No nerve-sparing right: N. (\%) & $7(22.6)$ \\
\hline Nerve-sparing left: N. (\%) & $25(80.6)$ \\
\hline No nerve-sparing left: N. (\%) & $6(19.4)$ \\
\hline \multicolumn{2}{|l|}{ Marginal resection: N. (\%) } \\
\hline Negative & $20(64.5)$ \\
\hline Positive & $11(35.5)$ \\
\hline \multicolumn{2}{|l|}{ Pathological TNM: N. (\%) } \\
\hline pT2aNxMx & $3(9.7)$ \\
\hline pT2bNxMx & $1(3.3)$ \\
\hline pT2cNxMx & $19(61.2)$ \\
\hline pT3aNxMx & $4(12.9)$ \\
\hline pT3bNxMx & $4(12.9)$ \\
\hline \multicolumn{2}{|l|}{ Gleason score: Median (range) } \\
\hline Sum & $7(4-9)$ \\
\hline
\end{tabular}

Netherlands) using a 32 multi-channel surface coil placed on the lower abdomen. All Patients were fasting with solid foods from 4 to 6 hours before the examination. Peristalsis was suppressed by administering $20 \mathrm{mg}$ intramuscular scopolamine butyl bromide (Buscopan, Boehringer Ingelheim, Yamagata, Japan). Patients were asked to empty the bladder about half of its volume in order to limit involuntary movements. The total duration of the examination was approximately 26 minutes.

The individual sequences and their duration are summarized in Table 1. All MRI investigations were evaluated independently at least by two radiologists who received brief training on PNP. For each RM survey, each operator performed at least two sets of measurements. Prior to the reconstruction of the hinterland, an image recording was performed to correct any artifacts from motion. Track reconstructions were performed directly on the MRI control console, using the Philips Fiber Track application includ- ed in the 4.1 .3 release of machine management software by designing regions of interest (ROI) of different shapes in the periprostatic adipose tissue using as reference the T2-dependent axial images fused with the DTI recorded images and taking care of not to include muscle fibers of the bladder or shutter muscles to avoid being included in the reconstruction.

The input parameters assigned to the software to perform the track-back reconstruction were: FA minimum of 0.15 , angle threshold of $45^{\circ}$, and the minimum length of $5 \mathrm{~mm}$. The output parameters calculated by the software were 5 for each ROI: (i) number of nerve fiber reconstructed (N), (ii) number of voxels (V), (iii) mean FA values, (iv) average ADC values, and (v) average length of reconstituted nerve fibers (L). The PNP modifications after RARP were evaluated by using T2-dependent axial images fused with DTI 6 ROI images in the periprostatic adipose tissue for each of the 2 RM controls. The ROIs, subdivided into right and left, have been positioned at three predetermined levels of the prostate: (i) prostate apex and plane equivalent to prostate apex in post RP MRI exam (Figure 1: A, B), (ii) middle third of prostate gland and plane equivalent to the third medium in post RP MRI exam (Figure 1: C, D), (iii) prostate base and plane equivalent to the prostate in post RP MRI exam (Figure 1: E, F).

\section{Statistical analysis}

All statistical analyses were performed using SAS statistical software, version 9.4 (SAS Institute, Inc., Cary, NC). Descriptive statistics included frequencies, means values with standard deviation $( \pm \mathrm{SD})$, median and range for continuous variables. Correlation coefficients were calculated using Spearman's correlation method (r). Results were considered to be statistically significant when $\mathrm{p} £ 0.05$ (two-sides).

\section{RESULTS}

The study included 31 patients who were assessed by pre-operative MRI and underwent RARP with nerve-sparing intent. Table 2 shows the clinical and pathologic features of the study population. Mean clinical features were as follows: age 64.03, prostate volume $45.72 \mathrm{cc}$, total prostate-specific antigen (PSA) 9.05. Neurovascular bundles were preserved on the right and left side in $77.4 \%$ and $80.6 \%$ of cases, respectively. Involvement of a surgical margin was detected in 11 cases $(35.5 \%)$. In the surgical specimen, the disease was extraprostatic in 8 cases $(28.8 \%)$ with extracapsular extension in $4(12.9 \%)$ and seminal vesicle invasion in 4 cases $(12,9 \%)$. The median Gleason score was 7 . Five of the 31 patients were not evaluated by MRI after RARP. Table 3 illustrates the results (mean \pm SD) of MRI measurements related to anisotropic fraction, number and length of fibers for each level of the prostate gland (base, mid-gland and apex) at six months from RARP in 26 patients. In par-

Table 3. Mean and Standard Deviation $( \pm \mathrm{SD})$ of anisotropic fraction, N. of fibers and fibers length for each level of the prostate gland at 6 months from radical prostatectomy nerve-sparing.

\begin{tabular}{|c|c|c|c|c|c|c|c|}
\hline & N. patients & \multicolumn{6}{|c|}{ Level of prostate gland } \\
\hline & & Base right & Base left & Mid right & Mid left & Apex right & Apex left \\
\hline & & Mean $( \pm \mathrm{SD})$ & Mean $( \pm$ SD) & Mean $( \pm$ SD $)$ & Mean $( \pm$ SD) & Mean $( \pm$ SD) & Mean $( \pm \mathrm{SD})$ \\
\hline Anisotropic fraction & 26 & $0.46( \pm 0.05)$ & $0.44( \pm 0.05)$ & $0.46( \pm 0.07)$ & $0.46( \pm 0.05)$ & $0.40( \pm 0.05)$ & $0.41( \pm 0.06)$ \\
\hline N. of fibers & 26 & $87.35( \pm 31.35)$ & $90.92( \pm 31.66)$ & $66.58( \pm 25.83)$ & $62.15( \pm 23.82)$ & $42.62( \pm 16.19)$ & $41.00( \pm 15.79)$ \\
\hline Fibers length & 26 & $13.16( \pm 2.63)$ & $13.18( \pm 2.36)$ & $14.17( \pm 2.96)$ & $13.79( \pm 2.85)$ & $14.38( \pm 3.27)$ & $13.84( \pm 2.95)$ \\
\hline
\end{tabular}


Table 4. Pearson correlation coefficients (r) between anisotropic fraction, N. of fibers, and fibers length for each level of the prostate gland and erectile dysfunction at 6 months from radical prostatectomy nerve-sparing.

\begin{tabular}{|c|c|c|c|c|c|c|}
\hline & \multicolumn{6}{|c|}{ Level of prostate gland } \\
\hline & Base right & Base left & Mid right & Mid left & Apex right & Apex left \\
\hline \multirow[t]{2}{*}{ N. patients } & 23 & 23 & 23 & 23 & 23 & 23 \\
\hline & \multicolumn{6}{|c|}{ Anisotropic fraction $(\mathrm{r})$} \\
\hline \multirow[t]{3}{*}{ Erectile dysfunction } & -0.42068 & -0.66120 & -0.25438 & -0.37252 & -0.38025 & -0.38739 \\
\hline & $\mathrm{p}=0.0456$ & $\mathrm{p}=0.0006$ & $\mathrm{p}=0.2415$ & $\mathrm{p}=0.0800$ & $\mathrm{p}=0.0735$ & $\mathrm{p}=0.0678$ \\
\hline & \multicolumn{6}{|c|}{ N. of fibers (r) } \\
\hline \multirow[t]{3}{*}{ Erectile dysfunction } & 0.25587 & 0.30807 & 0.13434 & -0.12201 & 0.33809 & -0.00850 \\
\hline & $\mathrm{p}=0.2386$ & $\mathrm{p}=0.1527$ & $\mathrm{p}=5411$ & $\mathrm{p}=0.5792$ & $\mathrm{p}=0.1146$ & $\mathrm{p}=0.9693$ \\
\hline & \multicolumn{6}{|c|}{ Fibers length (r) } \\
\hline \multirow[t]{2}{*}{ Erectile dysfunction } & 0.25737 & 0.19402 & 0.23542 & 0.30084 & 0.42546 & 0.15761 \\
\hline & $\mathrm{p}=0.2358$ & $\mathrm{p}=0.3750$ & $\mathrm{p}=0.2795$ & $\mathrm{p}=0.1631$ & $\mathrm{p}=0.0430$ & $\mathrm{p}=0.4726$ \\
\hline
\end{tabular}

ticular, at six months the number of fibers tracts was significantly decreased at base, mid-gland and apex for both right and left side ( $\mathrm{p}=0.01$ - data not shown). Three of the 26 cases who were evaluated by MRI before and six months after RARP did not have nerve-sparing surgery. Table 4 shows correlations of IIEF-5 score with MRI measurements including anisotropic fraction, number and length of fibers for each level of the prostate gland (base, mid-gland and apex) at six months from RARP with nerve-sparing intent in 23 patients. There was a significant negative correlation between IIEF-5 score and anisotropic fraction measurements at both right (Pearson's coefficient $=-0.420068 ; \mathrm{p}=0.0456)$ and left (Pearson's coefficient $=-0.66120 ; p=0.0006$ ) base of the prostate, respectively. It was not detected any significant correlation between IIEF-5 score and anisotropic fraction at the other levels of the gland as well as the number of fibers. Finally, the IIEF-5 score test correlated positively to the length of fibers located at the right apex of the gland (Pearson's coefficient $=0.42546$; $\mathrm{p}=0.0430$ ), but no significant correlation was detected at the other levels of the prostate. Table 5 shows correlations of ICIQ-SF score test with MRI measurements including anisotropic fraction, number and length of fibers for each level of the prostate gland (base, mid-gland and apex) at six months from RARP with nerve-sparing intent in 23 patients. As shown, no significant correlations were detected between ICIQ-SF score with any of the MRI measured parameters including anisotropic fraction, number and length of fibers for each level of the prostate gland.

\section{DISCUSSION}

The aim of the present study was to evaluate if DTI is able to detect the changes of the PNFs before and after prostatectomy and if these changes are related to postsurgical complications, such as urinary incontinence and erectile dysfunction. Despite conventional MRI has proven to be a useful modality for the diagnosis of extracapsular invasion of prostate cancer, the visualization of the PNFs remains still difficult ${ }^{16,17}$. Recently, Diffusion Tensor Imaging (DTI) has been uccessfully adopted for mapping of the PNFs' ${ }^{2,30,31}$. Although the recent introduction of "nerve-sparing" techniques has shown to be able to reduce the incidence of these complications in comparison with the "non-nerve-sparing" approaches ${ }^{5-8}$., their incidence is still not negligible and directly related to the number of the preserved fibers during prostatectomy ${ }^{10-11}$. In our study, in agreement with Kitajima

Table 5. Pearson correlation coefficients (r) between anisotropic fraction, N. of fibers, and fibers length for each level of the prostate gland and incontinence at 6 months from radical prostatectomy nerve-sparing.

\begin{tabular}{|c|c|c|c|c|c|c|}
\hline & \multicolumn{6}{|c|}{ Level of prostate gland } \\
\hline & Base right & Base left & Mid right & Mid left & Apex right & Apex left \\
\hline \multirow[t]{2}{*}{ N. patients } & 23 & 23 & 23 & 23 & 23 & 23 \\
\hline & \multicolumn{6}{|c|}{ Anisotropic fraction (r) } \\
\hline \multirow[t]{3}{*}{ Incontinence } & -0.14510 & -0.23853 & 0.00781 & -0.18938 & 0.21569 & -0.14532 \\
\hline & $\mathrm{p}=0.5089$ & $\mathrm{p}=0.2730$ & $\mathrm{p}=0.9718$ & $\mathrm{p}=0.3868$ & $\mathrm{p}=0.3229$ & $\mathrm{p}=0.5082$ \\
\hline & \multicolumn{6}{|c|}{ N. of fibers (r) } \\
\hline \multirow[t]{3}{*}{ Incontinence } & 0.17080 & 0.15209 & -0.06897 & -0.00938 & 0.09586 & -0.05818 \\
\hline & $\mathrm{p}=0.4359$ & $\mathrm{p}=0.4884$ & $\mathrm{p}=0.7514$ & $\mathrm{p}=0.9661$ & $\mathrm{p}=0.6635$ & $\mathrm{p}=0.7920$ \\
\hline & \multicolumn{6}{|c|}{ Fibers length (r) } \\
\hline \multirow[t]{2}{*}{ Incontinence } & 0.13591 & -0.17705 & -0.00833 & -0.06928 & 0.09009 & 0.25777 \\
\hline & $\mathrm{p}=0.5363$ & $\mathrm{p}=0.4190$ & $\mathrm{p}=0.9699$ & $\mathrm{p}=0.7535$ & $\mathrm{p}=0.6227$ & $\mathrm{p}=0.2350$ \\
\hline
\end{tabular}


et al. ${ }^{2}$, the number of fiber tracts after RARP was significantly decreased at the base, mid-gland, and apex for both right and left side $(\mathrm{p}<0.01)$. In this way, an interesting result of our series, which has not been studied before, is exclusively represented by significant negative correlation between IIEF-5 score and anisotropic fraction measurements at both rights $(\mathrm{p}=0.0456)$ and left $(\mathrm{p}=0.0006)$ base of the prostate. These results allow us to make some considerations. The first of all that the number of fibers is definitely essential for the recovery of erectile function and finally that the persistence of the fractional anisotropy of PNFs at six months is an indicator of probable erectile dysfunction. From a pathophysiologic point of view this aspect could be related to a difficult transmission of the nerve impulse, as normally happens when nerve fibers have a straight course. As known these findings confirm that erection occurs thanks to the preservation of pelvic plexus, as reported in the past by Walsh ${ }^{34}$, and that sphincteric urethra is not innervated predominantly by autonomic component. On the other hand in our study, this latter aspect is justified by the absence of a clear correlation between fractional anisotropy and urinary incontinence. In this regard, the role of the autonomic nervous component is somewhat uncertain and morphological studies in this direction show that the somatic nervous system, thanks to the pudendal nerve, is the predominant nervous component that is responsible for external sphincter innervation ${ }^{35}$. In any case, this study shows some limitations. The major one is the potential miscount of nerve fibers because the number of the track on DTI is not the real number of nerve fibers and because linear non-nerve structures such as fibromuscular tissue, arteries, and veins can concur to generate fiber tracts. Finally, the number of patients included in the study is still small and further largescale prospective studies are needed.

In conclusion, DTI of the periprostatic neurovascular fibers (PNFs) has demonstrated to be a useful and reproducible technique in detecting the changes of the PNFs induced by RARP. In particular, DTI seems to be a fascinating instrumental evaluation that in the future could play the role of predictive investigation for erection recovery after RARP.

\section{REFERENCES}

1. EAU - ESTRO - ESUR -Prostate cancer Guidelines 2017.

2. Takenaka A, Leung RA, Fujisawa M, Tewari (2010) Anatomy of autonomic nerve component in the male pelvis: the new concept from a perspective for robotic nerve-sparing radical prostatectomy. AK World J Urol. 2006 Jun;24(2):136-43. DOI: 10.1007/s00345-006-0102-2

3. Chabert CC, Merrilees DA, Neill MG, Eden CG (2008) Curtain dissection of the lateral prostatic fascia and potency after laparoscopic radical prostatectomy: a veil of mystery. BJU Int. 2008 May;101(10):1285-8. doi: 10.1111/j.1464410X.2008.07595.x

4. Vora AA, Marchalik D, Kowalczyk KJ, Nissim H, Bandi G, McGeagh KG, Lynch JH, Ghasemian SR, Verghese M, Venkatesan K, Borges P, Uchio EM, Hwang JJ (2013) Robotic-assisted prostatectomy and open radical retropubic prostatectomy for locally-advanced prostate cancer: multi-institution comparison of oncologic outcomes. Prostate Int. 2013;1(1):31-6. doi: 10.12954/PI.12001.

5. Labanaris AP, Witt JH, Zugor V (2012) Robotic-assisted radical prostatectomy in men $\geq 75$ years of age. Surgical, oncological and functional outcomes. Anticancer Res. 2012 May;32(5):2085-9.

6. Kiyoshima K, Yokomizo A, Yoshida T, Tomita K, Yonemasu H, Nakamura M, Oda Y, Naito S, Hasegawa Y Anatomical features of periprostatic tissue and its surroundings: a histological analysis of 79 radical retropubic prostatectomy specimens. Jpn J Clin Oncol. 2004Aug; 34(8):463-8. DOI: 10.1093/jjco/ hyh078

7. Ko WJ, Truesdale MD, Hruby GW, Landman J, Badani KK (2011) Impacting factors for recovery of erectile function within 1 year following robotic-assisted laparoscopic radical prostatectomy. J Sex Med. 2011 Jun;8(6):1805-12. doi: 10.1111/j.1743-6109.2011.02237.x.

8. Rabbani F, Stapleton AM, Kattan MW, Wheeler TM, Scardino PT Factors predicting recovery of erections after radical prostatectomy. J Urol. 2000 Dec;164(6):1929-34

9. Kitajima K, Takahashi S, Ueno Y, Miyake H, Fujisawa M, Sugimura K Visualization of periprostatic nerve fibers before and after radical prostatectomy using diffusion tensor magnetic resonance imaging with tractography. Clin Imaging. 2014 May-Jun;38(3):302-6. doi: 10.1016/j.

10. Weinreb JC, Barentsz JO, Choyke PL, Cornud F, Haider MA, Macura KJ, Margolis D, Schnall MD, Shtern F, Tempany CM, Thoeny HC, Verma S PI-RADS Prostate Imaging - Reporting and Data System: 2015, Version 2. Eur Urol.2016 Jan;69(1):1640. doi: 10.1016/j.eururo.2015.08.052.

11. Hull GW, Rabbani F, Abbas F, Wheeler TM, Kattan MW, Scardino PT Cancer control with radical prostatectomy alone in 1,000 consecutive patients. J Urol. 2002Feb;167(2 Pt 1):52834.

12. Bloch BN, Furman-Haran E, Helbich TH, Lenkinski RE, Degani H, Kratzik C, Susani M, Haitel A, Jaromi S, Ngo L, Rofsky NM Prostate cancer: accurate determination of extracapsular extension with high-spatial-resolution dynamic contrast-enhanced and T2-weighted MR imaging - initial results. Radiology 2007; 245:176-85. DOI: 10.1148/radiol.2451061502

13. Hricak H, Wang L, Wei DC, Coakley FV, Akin O, Reuter VE, Gonen M, Kattan MW, Onyebuchi CN, Scardino PT The role of preoperative endorectal magnetic resonance imaging in the decision regarding whether to preserve or resect neurovascular bundles during radical retropubic prostatectomy. Cancer. 2004; 100(12): p. 2655-63.

14. McClure TD, Margolis DJ, Reiter RE, Sayre JW, Thomas MA, Nagarajan R, Gulati M, Raman SS Use of MR imaging to determine preservation of the neurovascular bundles at robotic-assisted laparoscopic prostatectomy. Radiology 2012; 262(3): p. 874-83. doi: 10.1148/radiol.11103504

15. Le Bihan D, Breton E, Lallemand D, Grenier P, Cabanis E, Laval-Jeantet M MR imaging of intravoxel incoherent motions: application to diffusion and perfusion in neurologic disorders. Radiology.1986; 161(2): p. 401-7. DOI: 10.1148/ radiology.161.2.3763909

16. Ahn S, Lee SK Diffusion tensor imaging: exploring the motor networks and clinical applications. Korean J Radiol. 2012; 12(6): p. 651-61. DOI: 10.3348/kjr.2011.12.6.651

17. Yu CS, Li KC, Xuan Y, Ji XM, Qin W Diffusion tensor tractography in patients with cerebral tumors: a helpful technique for neurosurgical planning and postoperative assessment. Eur J Radiol. 2005; 56(2): p. 197-204. DOI: 10.1016/j. ejrad.2005.04.010

18. Jones, D.K. The effect of gradient sampling schemes on measures derived from diffusion tensor MRI: a Monte Carlo study. Magn Reson Med. 51(4): p. 807-15. DOI: 10.1002/mrm.20033

19. Yamada K, Kizu O, Mori S, Ito H, Nakamura H, Yuen S, Kubota T, Tanaka O, Akada W, Sasajima H, Mineura K, Nishimura $\mathrm{T}$ Brain fiber tracking with clinically feasible diffusion-tensor MR imaging: initial experience. Radiology 2004; 227(1): p. 295-301. DOI: 10.1148/radiol.2271020313

20. Okada T, Miki Y, Fushimi Y, Hanakawa T, Kanagaki M, Yamamoto A, Urayama S, Fukuyama H, Hiraoka M, Togashi K Diffusion-tensor fiber tractography: intraindividual comparison of 3.0-T and 1.5-T MR imaging. Radiology. 2006; 238(2): p. 668-78. DOI: 10.1148/radiol.2382042192

21. Kulikova S, Hertz-Pannier L, Dehaene-Lambertz G, Buzmakov A, Poupon C, Dubois J Multi-parametric evaluation of the white matter maturation. Brain Struct Funct, 2015; 220(6): p. 3657-72. DOI: 10.1007/s00429-014-0881-y

22. Löbel U, Sedlacik J, Güllmar D, Kaiser WA, Reichenbach JR, Mentzel HJ. Diffusion tensor imaging: the normal evolution of ADC, RA, FA, and eigenvalues studied in multiple anatomical regions of the brain. Neuroradiology.2009; 51(4): 253-63. DOI: $10.1007 / \mathrm{s} 00234-008-0488-1$

23. Fabri M, Pierpaoli C, Barbaresi P, Polonara G Functional topography of the corpus callosum investigated by DTI and fMRI. World J Radiol, 2014. 6(12): p. 895-906. DOI: 10.4329/ wjr.v6.i12.895

24. Lin CC, Tsai MY, Lo YC, Liu YJ, Tsai PP, Wu CY, Lin CW, Shen WC, Chung HW Reproducibility of corticospinal diffusion tensor tractography in normal subjects and hemiparetic stroke 
patients. Eur J Radiol 2013; 82(10): p. 610-6. DOI: 10.1016/j. ejrad.2013.06.016

25. Vargas MI, Viallon M, Nguyen D, Delavelle J, Becker M Diffusion tensor imaging (DTI) and tractography of the brachial plexus: feasibility and initial experience in neoplastic conditions. neuroradiology. 2010; 52(3): p. 237-45. doi: 10.1007/ s00234-009-0643-3.

26. Finley DS, Ellingson BM, Natarajan S, Zaw TM, Raman SS, Schulam P, Reiter RE, Margolis D Diffusion tensor magnetic resonance tractography of the prostate: feasibility for mapping periprostatic fibers. Urology. 2012; 80(1): p. 219-23. doi: 10.1016/j.urology.2012.03.027.

27. Panebianco V1, Barchetti F, Sciarra A, Marcantonio A, Zini C, Salciccia S, Collettini F, Gentile V, Hamm B, Catalano C In vivo $3 \mathrm{D}$ neuroanatomical evaluation of periprostatic nerve plexus with 3T-MR Diffusion Tensor Imaging. Eur J Radiol. 2013; 82(10): p. 1677-82. doi: 10.1016/j.ejrad.2013.05.013

28. Farrell JA, Landman BA, Jones CK, Smith SA, Prince JL, van Zijl PC, Mori S Effects of signal-to-noise ratio on the accuracy and reproducibility of diffusion tensor imaging-derived fractional anisotropy, mean diffusivity, and principal eigenvector measurements at 1.5 T. J Magn Reson Imaging. 2007; 26(3): p. 756-67. DOI: $10.1002 / \mathrm{jmri} .21053$

29. D'Amico AV, Whittington R, Malkowicz SB, Schultz D, Blank K, Broderick GA, Tomaszewski JE, Renshaw AA, Kaplan I, Beard CJ, Wein Biochemical outcome after radical prostatectomy, external beam radiation therapy, or interstitial radiation therapy for clinically localized prostate cancer. JAMA; 1998; 280:969-74;

30 Montorsi F, Wilson TG, Rosen RC, Ahlering TE, Artibani W, Carroll PR, Costello A, Eastham JA, Ficarra V, Guazzoni G, Menon M, Novara G, Patel VR, Stolzenburg JU, Van der Poel H, Van Poppel H, Mottrie A Best practices in robot-assisted radical prostatectomy: recommendations of the Pasadena Consensus Panel. Eur Urol 2012; 62:368-381.DOI: 10.1016/j.eururo.2012.11.036
31. Menon M, Tewari A, Peabody J Vattikuti Institute prostatectomy: technique. J Urol 2003; 169:2289-92. DOI: 10.1097/01. ju.0000067464.53313.dd

32. Rhoden EL, Teloken C, Sogari PR, Vargas SC The use of the simplified International Index of Erectile Function (IIEF-5) as a diagnostic tool to study the prevalence of erectile dysfunction. Int J Impot Res 2002; 14:245-250. DOI: 10.1038/ sj.ijir.3900859

33. Avery K, Donovan J, Peters TJ, Shaw C, Gotoh M, Abrams P ICIQ: a brief and robust measure for evaluating the symptoms and impact of urinary incontinence. Neurourol Urodyn. 2004;23(4):322-30. DOI: 10.1002/nau.20041

34. Rogers CG, Trock BP, Walsh P Preservation of accessory pudendal arteries during radical retropubic prostatectomy: surgical technique and results. Urology. 2004 Jul;64(1):148-51. DOI: $10.1016 /$ j.urology.2004.02.035

35. T, Sooriakumaran P, Takenaka A, Tewari A Neural supply of the male urethral sphincter: comprehensive anatomical review and implications for continence recovery after radical prostatectomy. Bessede. World J Urol. 2017 Apr;35(4):549-565. doi: 10.1007/s00345-016-1901

\section{DISCLOSURE STATEMENTS}

There was no conflict of interest, informed patient consent was obtained, and the study was approved by the local ethical committee. The authors of the publication did not receive any financial support by any grant/research sponsor

\author{
Corresponding Author: \\ Prof. Salvatore Siracusano \\ Department of Urology - University of Verona \\ Piazzale Stefani 1 - 37100 Verona - Italy \\ email: salvatore.siracusano@univr.it
}

\section{Multidisciplinary UroGyneProcto Editorial Comment}

To improve the integration among the three segments of the pelvic floor, some of the articles published in Pelviperineology are commented on by Urologists, Gynecologists, Proctologists/Colo Rectal Surgeons or other Specialists, with their critical opinion and a teaching purpose. Differences, similarities and possible relationships between the data presented and what is known in the three fields of competence are stressed, or the absence of any analogy is indicated. The discussion is not a peer review, it concerns concepts, ideas, theories, not the methodology of the presentation.

Gyneco... In analogy with the surgical procedure of radical prostatectomy, the radical hysterectomy operation for cancer is responsible of numerous negative effects on sexual functioning ${ }^{1}$. This is due to the elimination of a large part of pelvic ligaments and pelvic autonomic nerves notoriously involved in clitoral as penile erection (parasympathetic nervous system), and in female orgasm and ejaculation (orthosympathetic nervous system). These autonomic nerves are located in the sacro-coccygeal plexus in the pelvis. Prostate and uterus are organs embriologically correlated, consequently their radical removal causes gender similar sexual, urinary and anorectal dysfunctions. In fact women following radical hysterectomy have a high incidence of sexual dysfunctions (sexual desire, sexual arousal, orgasmic, and sexual pain disorders, data obtained by a self-reported sexual function questionnaire). The preoperative, 1 - and 2-year postoperative, sexual dysfunction rates were $50.5 \%, 86.9 \%$, and $92.3 \%$ respectively becoming eventually stable as shown in the recent study of Wang and Chen ${ }^{2}$ and age, preserved ovary, preserved posterior vaginal wall length, preoperative stage, radiotherapy, and education background were risk factors associated with sexual dysfunction.

A metanalysis of Xue and $\mathrm{Zhu}^{3}$ demonstrated that the nerve sparing radical hysterectomy was associated with less bladder and anorectal dysfunction and a higher score of Femal Sexual Function Index (FSFI) with a similar rate of cancer recurrence. To confirm the result that Siracusano founded in men, it would be very interesting a study on use of Diffusion Tensor Imaging tecnique on MRI in the prognosis of sexual dysfunction after radical hysterectomy.

\section{REFERENCES}

1. Danesh M, Hamzehgardeshi Z2, Moosazadeh M3, Shabani-Asrami F4.The Effect of Hysterectomy on Women's Sexual Function: a Narrative Review. Med Arh. 2015 69(6):387-392 . doi: 10.5455/medarh.2015.69.387-392

2. Wang X1,2, Chen C3, Liu P1, Li W1, Wang L1, Liu Y1.The 
morbidity of sexual dysfunction of 125 Chinese women following different types of radical hysterectomy for gynaecological malignancies. Arch Gynecol Obstet 2018 Feb;297(2):459466. doi: 10.1007/s00404-017-4625-0. Epub 2017 Dec 27.

3. Xue Z,Zhu X, Teng Y.Comparison of Nerve Sparing Radical Hysterectomy and Radical Hysterectomy: a Systematic Review and Meta-Analysis.Cell Physiol Biochem 2016;38(5):1841-50. doi: 10.1159/000443122. Epub 2016 May 9.
CHIARA ALESSI

Obstetrics and Gynecologic Unit. AO Padova, Italy

Correspondence:

chiara.alessi@aopd.veneto.it
Procto... Surgery for rectal cancer may result in physiologic and psychologic changes that alter a patient's sexual functioning and quality of life. Most studies examine the male sexual issues of erectile dysfunction and retrograde ejaculation, while female sexual dysfunction is relatively ignored. Women with rectal cancer are reluctant to talk about their sexuality, and if they do, it's on dyspareunia. Furthermore, validated instruments for measuring sexual functioning have seldom been used in studies of sexual changes after rectal cancer surgery ${ }^{1}$. Data prospectively collected on 295 women who underwent rectal cancer excision $^{2}$, mean age 60.9 years, showed significant impairments in female urinary and sexual outcomes; around half of all cancer survivors experience a decrease in sexual functioning and changes in body image, and with colorectal cancer, the rates can be even higher. In males total mesorectal surgery affects erection and ejaculation in over $82 \%{ }^{3}$. Women after rectal cancer surgery are significantly less likely to be sexually active than prior to surgery, their problems being multi-factorial. The type of surgery (abdominoperineal excision vs anterior resection) impact sexual function with less frequent coitus, and being less likely to achieve arousal or orgasm.

\section{REFERENCES}

1. Samantha K. Hendren, MD,* Brenda I. O'Connor, RN,* Maria Liu, BSc, et al Prevalence of male and female sexual dysfunction is high following surgery for rectal cancer. Ann Surg. 2005; 242(2): 212-223.

2. Tekkis PP, Cornish JA, Remzi FH et al. Measuring sexual and urinary outcomes in women after rectal cancer excision. Dis C R 2009; 52: 46-54

3. Averyt JC, Nishimoto PW . Addressing sexual dysfunction in colorectal cancer survivorship care J Gastrointest Oncol. 2014 Oct; 5(5): 388-394.

\section{GIUSEPPE DODI}

Colorectal surgeon, University of Padova, Italy

\section{Correspondence:}

giuseppe.dodi@unipd.it 